\title{
The XIPHOS diffraction facility for extreme sample conditions
}

Michael R. Probert, ${ }^{* a}$ Craig M. Robertson, ${ }^{a}$ Jonathan A. Coome, ${ }^{a}$ Judith A.K. Howard, ${ }^{a}$ Brian Michell ${ }^{\mathrm{b}}$ and Andrés E. Goeta ${ }^{a}$

\section{Supplementary information}




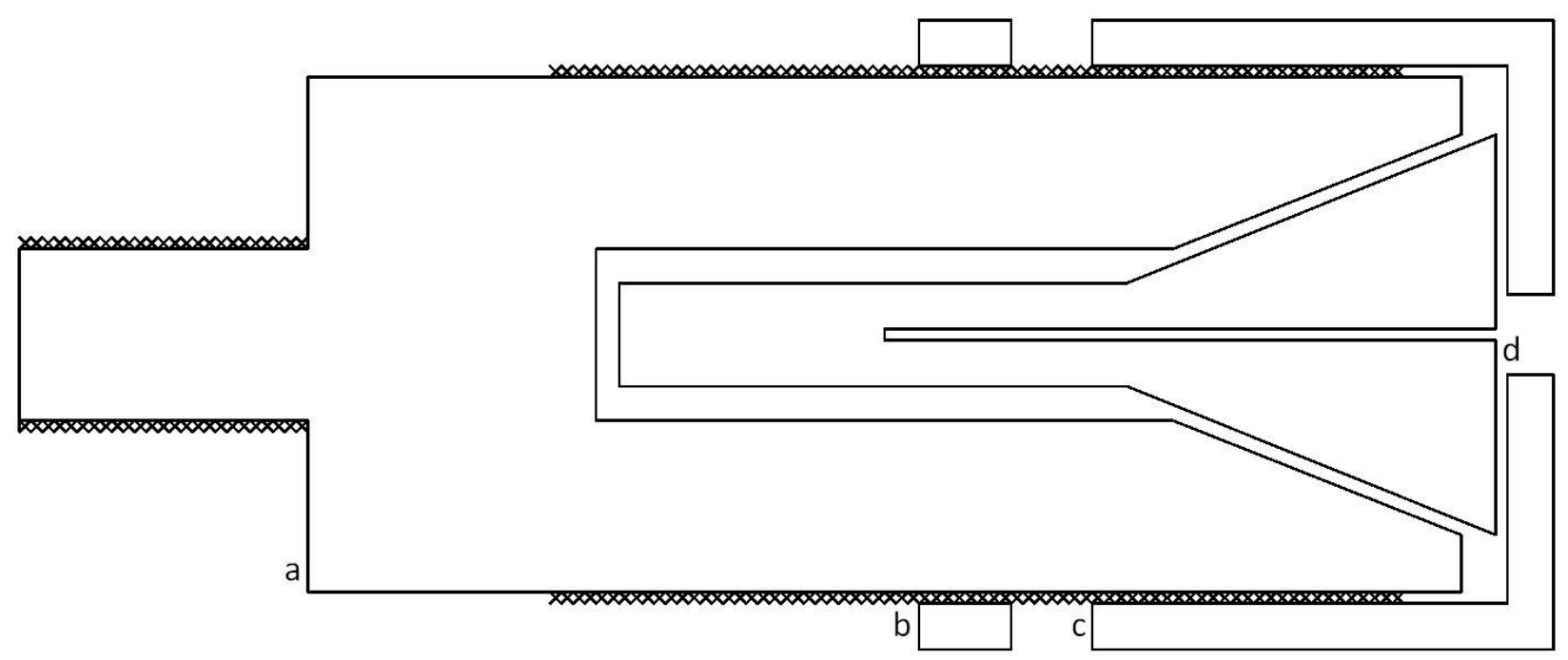

SI 1: Schematic diagram of the modified sample mount for the 3-stage Displex (a main body, b - clamp locking mechanism, c - chuck clamp, d - micro chuck from $0.5 \mathrm{~mm}$ propelling pencil) 


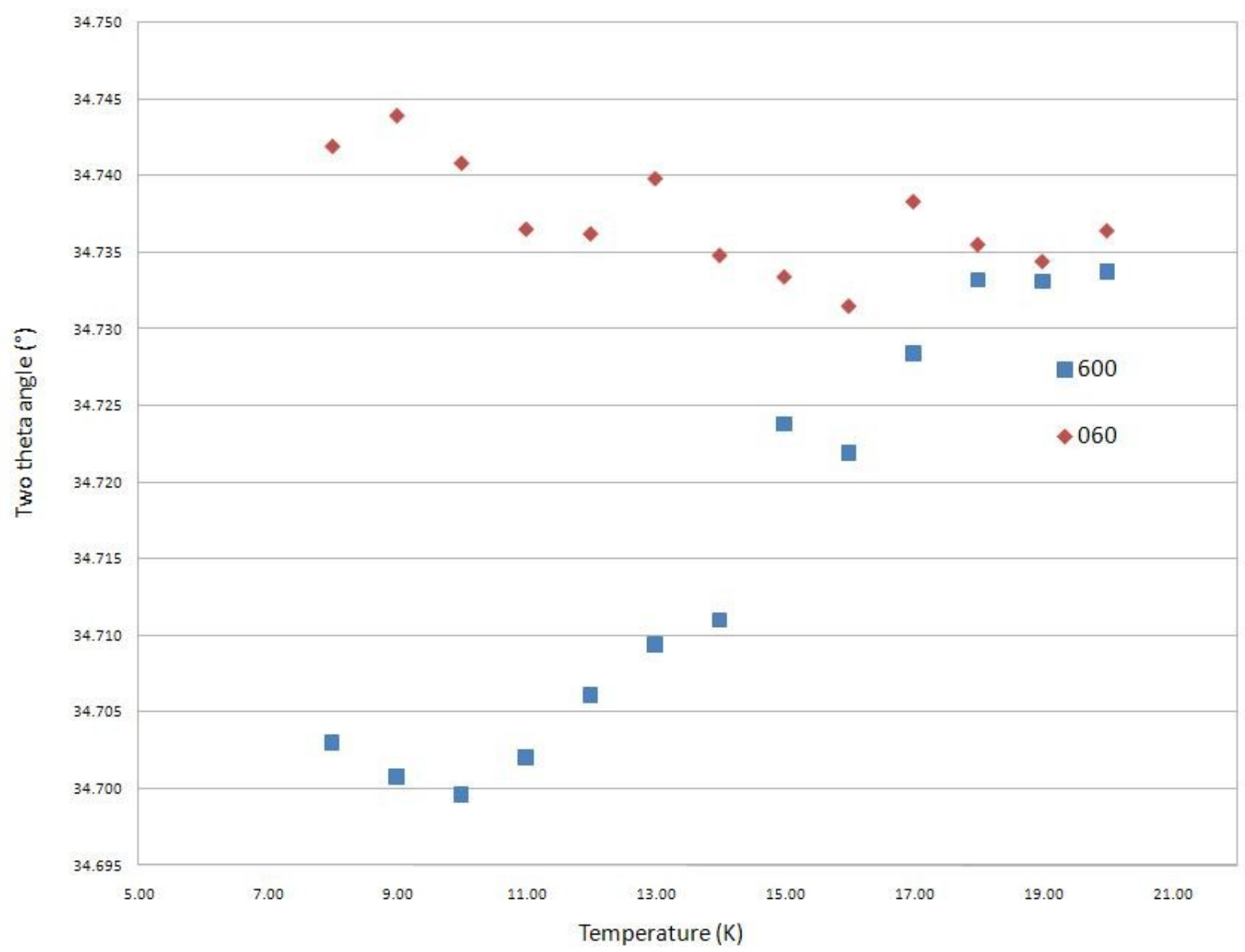

SI 2: Graph showing DyV04 phase transition by analyzing the change in two-theta angle of the 600 and 060 reflection centroids with respect to temperature. 


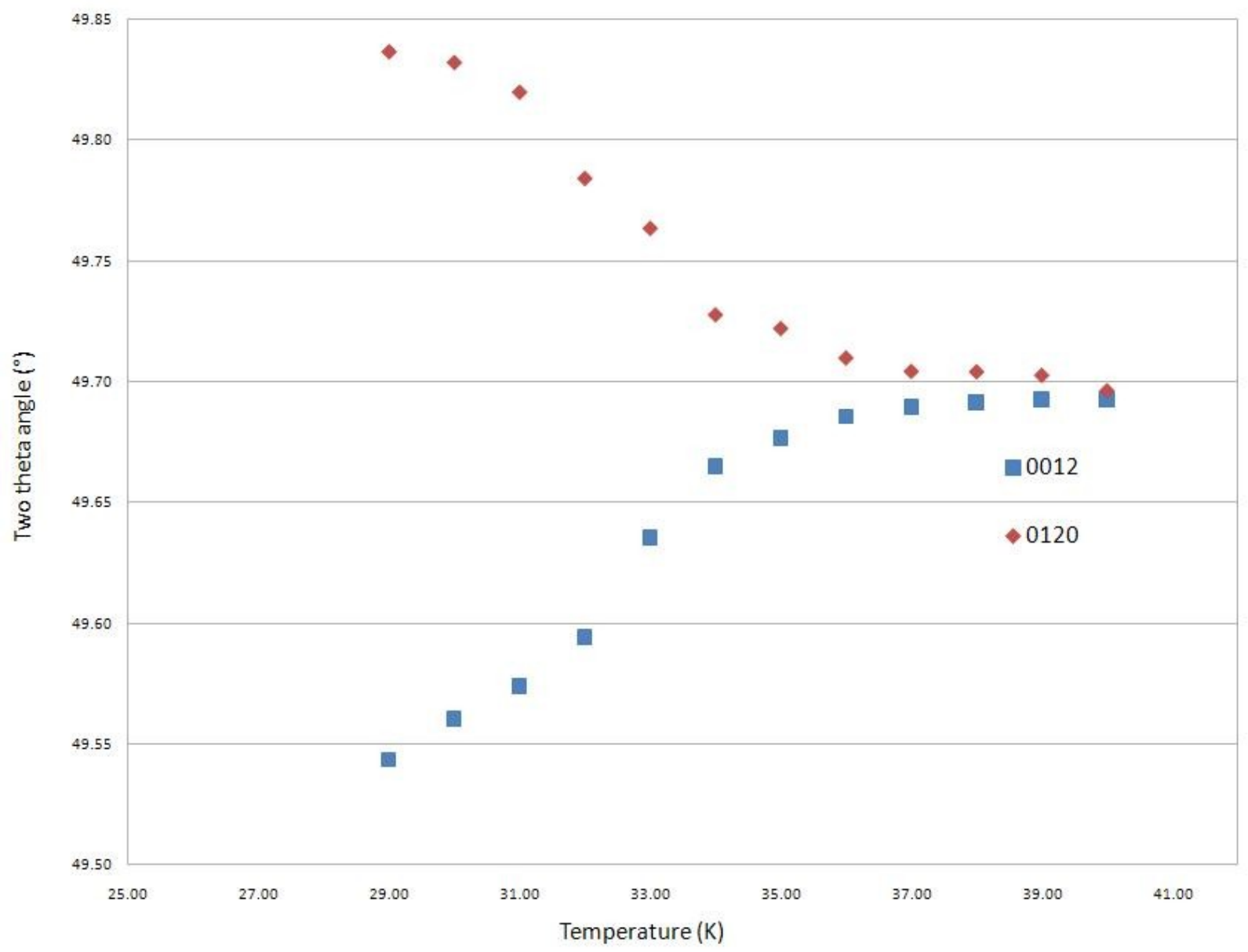

SI 3: Graph showing TbVO4 phase transition by analyzing the change in two-theta angle of the 0012 and 0120 (in the orthorhombic cell setting) reflection centroids with respect to temperature. 


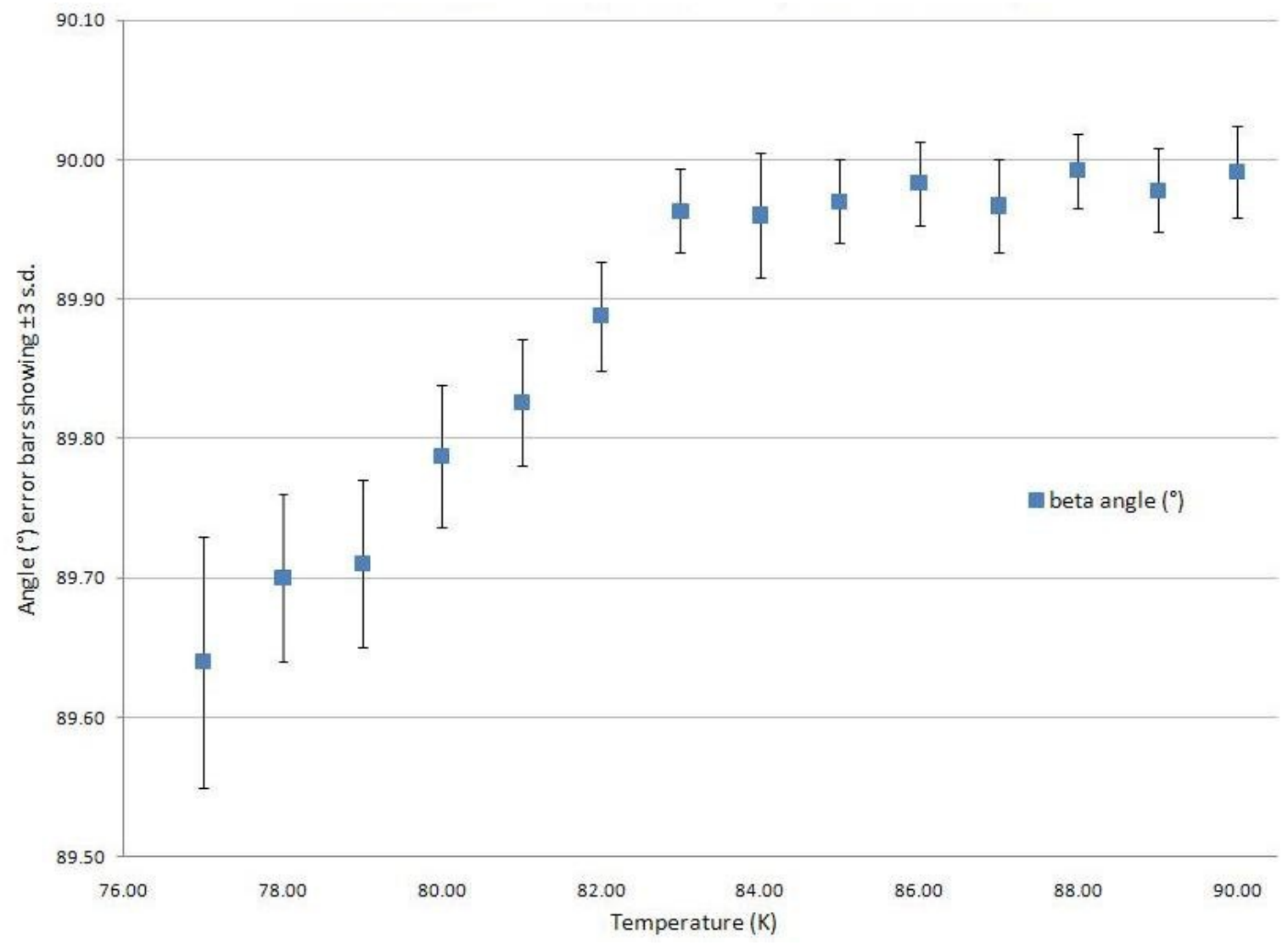

SI 4: Graph showing Benzil phase transition, analyzing the change in beta angle with respect to temperature 


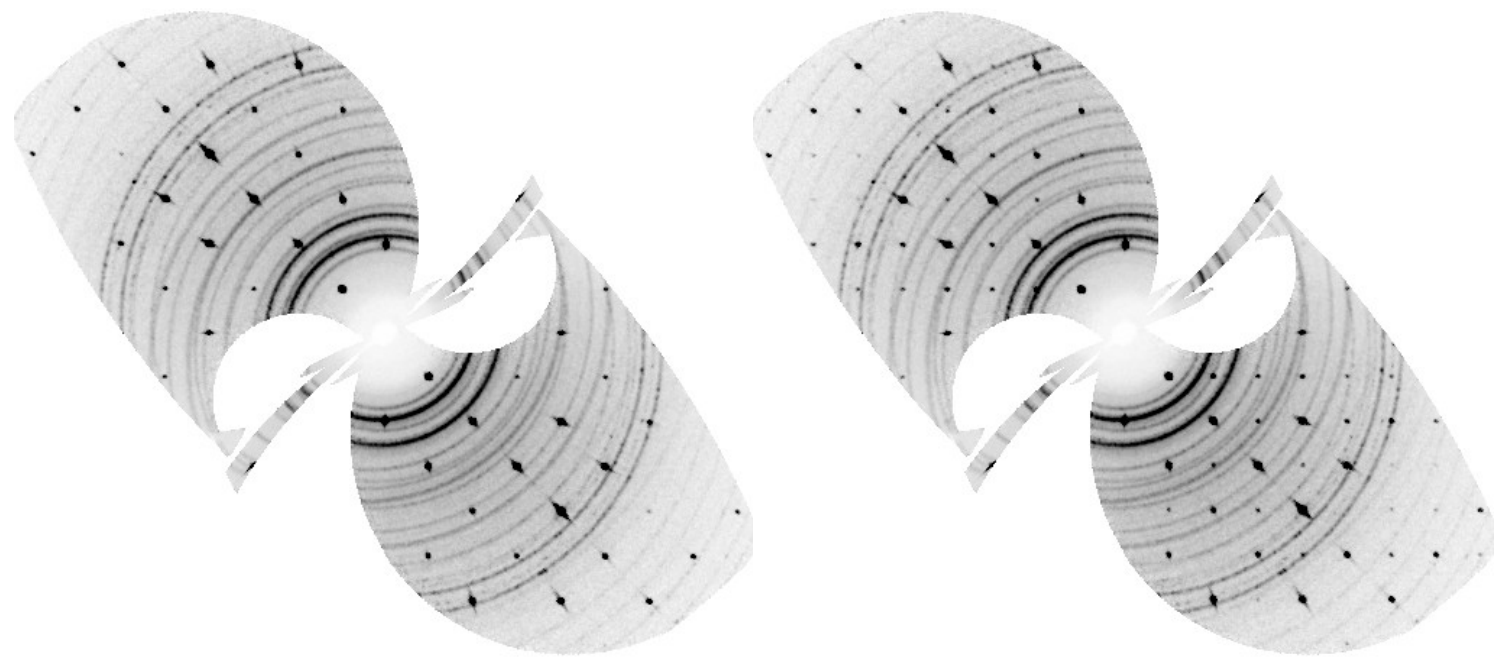

SI 5: Simulated precession images for the hkO planes of $\mathrm{NH} 4 \mathrm{H} 2 \mathrm{PO}$ at $148 \mathrm{~K}$ (left) and $147 \mathrm{~K}$ (right), showing the appearance of the I-centered absences below the structural phase transition. 


\begin{tabular}{cccccccccc}
\hline $\begin{array}{c}\text { Scan } \\
\text { Type }\end{array}$ & $\begin{array}{c}\text { Distance } \\
(\mathbf{m m})\end{array}$ & $\mathbf{2 \theta}\left(^{\circ}\right)$ & $\mathbf{\Omega}\left(^{\circ}\right)$ & $\mathbf{\Phi}\left(^{\circ}\right)$ & $\chi\left(^{\circ}\right)$ & $\begin{array}{c}\text { Scan } \\
\text { width }\left({ }^{\circ}\right)\end{array}$ & $\begin{array}{c}\text { Scan } \\
\text { time (s) }\end{array}$ & $\begin{array}{c}\text { Image } \\
\text { width } \\
\left({ }^{\circ}\right)\end{array}$ & $\begin{array}{c}\text { Scan } \\
\text { direction }\end{array}$ \\
\hline phi -scan & 80.000 & 30.000 & 30.000 & -102.500 & 180.000 & 25.00 & 10.00 & 0.50 & positive \\
phi-scan & 80.000 & 30.000 & 30.000 & -12.500 & 180.000 & 25.00 & 10.00 & 0.50 & positive \\
phi -scan & 80.000 & 30.000 & 30.000 & 77.500 & 180.000 & 25.00 & 10.00 & 0.50 & positive \\
phi-scan & 80.000 & 30.000 & 30.000 & 167.500 & 180.000 & 25.00 & 10.00 & 0.50 & positive \\
\hline
\end{tabular}

SI Table 1: XIPHOS crystal centring scan details. 